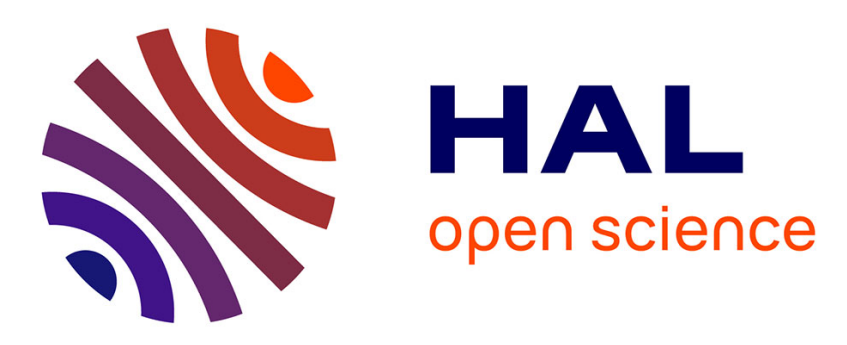

\title{
Origin band of the first photoionizing transition of hydrogen isocyanide
}

Bérenger Gans, Gustavo A Garcia, Séverine Boyé-Péronne, Stephen T Pratt, Jean-Claude Guillemin, Alfredo Aguado, Octavio Roncero, Jean-Christophe Loison

\section{To cite this version:}

Bérenger Gans, Gustavo A Garcia, Séverine Boyé-Péronne, Stephen T Pratt, Jean-Claude Guillemin, et al.. Origin band of the first photoionizing transition of hydrogen isocyanide. Physical Chemistry Chemical Physics, 2019, 21 (5), pp.2337-2344. 10.1039/c8cp07737a . hal-02072205

\section{HAL Id: hal-02072205 https://hal.science/hal-02072205}

Submitted on 28 Jun 2019

HAL is a multi-disciplinary open access archive for the deposit and dissemination of scientific research documents, whether they are published or not. The documents may come from teaching and research institutions in France or abroad, or from public or private research centers.
L'archive ouverte pluridisciplinaire HAL, est destinée au dépôt et à la diffusion de documents scientifiques de niveau recherche, publiés ou non, émanant des établissements d'enseignement et de recherche français ou étrangers, des laboratoires publics ou privés. 

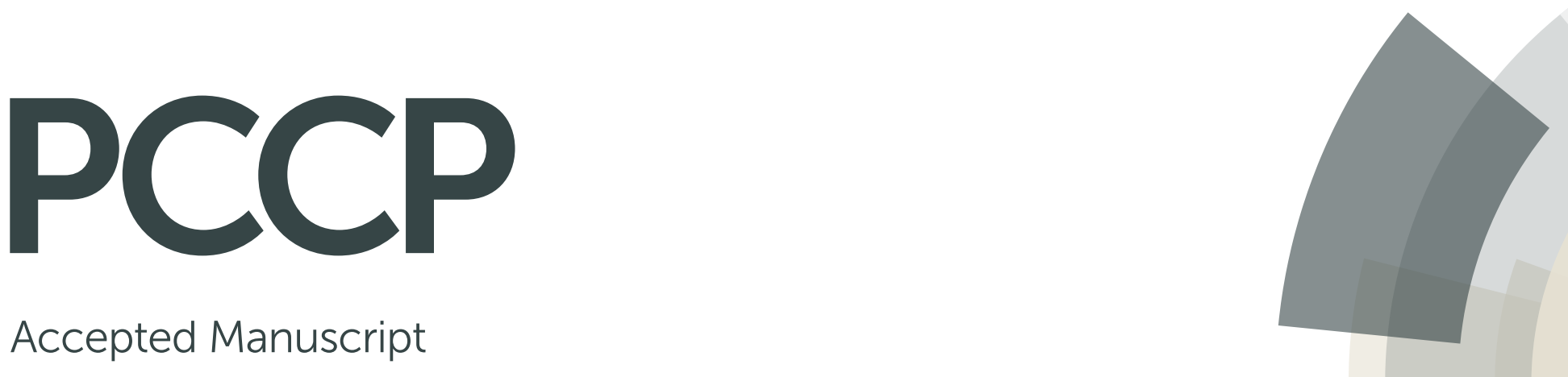

Accepted Manuscript

This article can be cited before page numbers have been issued, to do this please use: B. Gans, G. A. Garcia, S. Boyé-Péronne, S. T. Pratt, J. Guillemin, A. Aguado, O. Roncero and J. Loison, Phys. Chem. Chem. Phys., 2019, DOI: 10.1039/C8CP07737A.

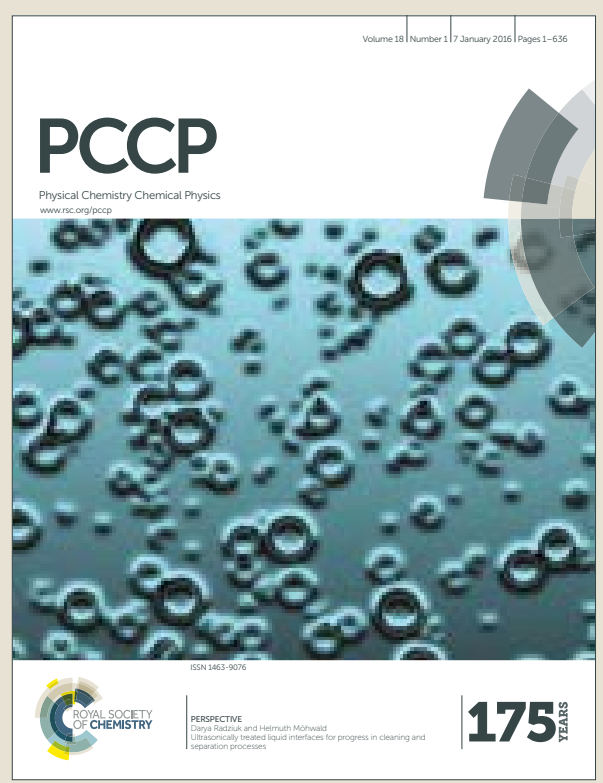

This is an Accepted Manuscript, which has been through the Royal Society of Chemistry peer review process and has been accepted for publication.

Accepted Manuscripts are published online shortly after acceptance, before technical editing, formatting and proof reading. Using this free service, authors can make their results available to the community, in citable form, before we publish the edited article. We will replace this Accepted Manuscript with the edited and formatted Advance Article as soon as it is available.

You can find more information about Accepted Manuscripts in the author guidelines.

Please note that technical editing may introduce minor changes to the text and/or graphics, which may alter content. The journal's standard Terms \& Conditions and the ethical guidelines, outlined in our author and reviewer resource centre, still apply. In no event shall the Royal Society of Chemistry be held responsible for any errors or omissions in this Accepted Manuscript or any consequences arising from the use of any information it contains. 


\title{
Journal Name
}

\section{ARTICLE TYPE}

Cite this: DOI: $10.1039 / x x x x x x x x x x$

\section{Origin band of the first photoionizing transition of hy- drogen isocyanide}

\author{
Bérenger Gans, ${ }^{* a}$ Gustavo A. Garcia,${ }^{b}$ Séverine Boyé-Péronne, ${ }^{a}$ Stephen T. Pratt ${ }^{c}$ \\ Jean-Claude Guillemin, ${ }^{d}$ Alfredo Aguado, ${ }^{e}$ Octavio Roncero, ${ }^{f}$ and Jean-Christophe \\ Loison ${ }^{g}$
}

Received Date
Accepted Date

DOI: $10.1039 / x x x x x x x x x x$

www.rsc.org/journalname
The photoelectron spectrum of the $\mathrm{X}^{1} \Sigma^{+} \rightarrow \mathrm{X}^{+2} \Sigma^{+}$ionizing transition of hydrogen isocyanide (HNC) is measured for the first time at a fixed photon energy (13 eV). The assignment of the spectrum is supported by wave-packet calculations simulating the photoionization transition spectrum and using ab initio calculations of the potential energy surfaces for the three lowest electronic states of the cation. The photoelectron spectrum allows the retrieval of the fundamental of the $\mathrm{CN}$ stretching mode of the cationic ground state $\left(\tilde{v}_{3}=2260 \pm 80 \mathrm{~cm}^{-1}\right)$ and the adiabatic ionization energy of hydrogen isocyanide: $I E(\mathrm{HNC})=12.011 \pm 0.010 \mathrm{eV}$, which is far below that of $\mathrm{HCN}(I E(\mathrm{HCN})=13.607 \mathrm{eV})$. In light of this latter result, the thermodynamics of the $\mathrm{HCN}^{+} / \mathrm{HNC}^{+}$ isomers is discussed and a short summary of the values available in the literature is given.

\section{Introduction}

The $[\mathrm{H}, \mathrm{C}, \mathrm{N}]$ molecular system is one of the fundamental model systems in molecular physics, in particular for its $\mathrm{HCN} \leftrightarrow \mathrm{HNC}$ hydrogen shift isomerization reaction. ${ }^{1}$ In the interstellar medium, the hydrogen isocyanide molecule (HNC) is omnipresent ${ }^{2}-9$ with a comparable abundance to that of the hydrogen cyanide (HCN), its more stable isomer. ${ }^{[0]}$ These two molecules and their corresponding cations are involved in numerous reactions. For instance, Loison et al. $\frac{10}{10}$ have listed more than 50 reactions of these species in a chemical network describing dark molecular clouds. It is thus crucial to have a good knowledge of the thermochemical data to establish the most important sources and sinks of these species. The $\mathrm{HCN}^{+} / \mathrm{HNC}^{+}$ratio is a puzzling matter in interstellar media. $\mathrm{HCN}^{+} / \mathrm{HNC}^{+}$isomers are produced through various ion-molecule reactions: $\mathrm{H}^{+}+\mathrm{HCN}, \mathrm{H}^{+}+\mathrm{HNC}, \mathrm{CN}^{+}+\mathrm{H}_{2}, \mathrm{~N}$

\footnotetext{
${ }^{a}$ Institut des Sciences Moléculaires d'Orsay (ISMO), UMR 8214 CNRS, Univ. Paris-Sud, Université Paris-Saclay, F-91405 Orsay, France

${ }^{b}$ Synchrotron SOLEIL, L'Orme des Merisiers, Saint Aubin BP 48, F-91192 Gif sur Yvette Cedex, France

${ }^{c}$ Chemical Sciences and Engineering Division, Argonne National Laboratory, Lemont, Illinois 60439, USA

d Univ Rennes, Ecole Nationale Supérieure de Chimie de Rennes, CNRS, ISCR UMR6226, F-35000 Rennes, France

e Departamento de Química Física Aplicada, Facultad de Ciencias M-14, Unidad Asociada IFF-CSIC, Universidad Autónoma de Madrid, 28049 Madrid, Spain

${ }^{f}$ Instituto de Física Fundamental (IFF-CSIC), C.S.I.C., Serrano 123, 28006 Madrid, Spain

${ }^{g}$ Institut des Sciences Moléculaires, UMR 5255 CNRS-Université de Bordeaux, Bât. A12, 351 cours de la Libération, F-33405 Talence Cedex, France

* corresponding author: berenger.gans@u-psud.fr
}

$+\mathrm{CH}_{3}^{+}, \mathrm{CN}+\mathrm{H}_{3}^{+}$. In dense molecular clouds, knowledge of the specific isomer $\mathrm{HCN}^{+} / \mathrm{HNC}^{+}$is not essential, because both are expected to react rapidly with $\mathrm{H}_{2}$ leading to $\mathrm{HCNH}^{+}+\mathrm{H} \cdot \sqrt{10[11}$ For diffuse molecular clouds, however, hydrogen is primarily present as $\mathrm{H}$ atoms, and the main destruction pathway for $\mathrm{HCN}^{+} / \mathrm{HNC}^{+}$ is electronic dissociative recombination, for which the rate is 30 times larger for $\mathrm{HCN}^{+}$than $\mathrm{HNC}^{+}{ }^{12}$ For the reaction with $\mathrm{H}^{+}$, the ionization energy $(I E)$ is $13.598 \mathrm{eV}$ for $\mathrm{H}^{13}, 13.607 \mathrm{eV}$ for $\mathrm{HCN}, 14$ and around $12 \mathrm{eV}$ for HNC (see Section 3.2). Then, as the rate constant for the $\mathrm{H}^{+}+\mathrm{HCN}$ reaction is very high at room temperature, 11 close to the Langevin one, the product is likely $\mathrm{HNC}^{+}$and not $\mathrm{HCN}^{+}$. The $\mathrm{CN}^{+}+\mathrm{H}_{2}$ reaction has been studied by Petrie et al. 15 and Scott et al. ${ }^{16}$ They found that it is a fast reaction producing equal amounts of $\mathrm{HCN}^{+}$and $\mathrm{HNC}^{+}$, the isomers being identified through their different reactivity with $\mathrm{CO}$ and $\mathrm{CO}_{2}$. The $\mathrm{N}+\mathrm{CH}_{3}^{+}$reaction is supposed to lead only to $\mathrm{HCN}^{+}$isomer. ${ }^{17 \mid 18}$ There is no data for the $\mathrm{CN}+\mathrm{H}_{3}^{+}$reaction but considering the potential energy curves, both isomers should be produced because both $\mathrm{H}-\mathrm{CN}^{+}$and $\mathrm{H}-\mathrm{NC}^{+}$approaches are barrierless. ${ }^{12}[19$ It is then important to introduce both isomers in astrochemical networks with relevant rates and branching ratios.

Although the enthalpies of formation of $\mathrm{HCN}^{20121}$ and $\mathrm{HCN}^{+}$ (see Section 3.4) are well known, the values for $\mathrm{HNC}$ and $\mathrm{HNC}^{+}$ are less certain. In particular, although a few theoretical $22-26$ and experimental 2728 works are available in the literature, the value of the ionization energy of HNC is still uncertain, as reflected in the range of values reported in the literature $\left(I E_{\text {calc. }}=[11.48-\right.$ $12.01] \mathrm{eV}$ and $\left.I E_{\text {exp. }}=[12.04-12.5] \mathrm{eV}\right)$.

The main drawback of this lack of data is that the two iso- 
mers are often described as same species with the same thermodynamic properties. This crude approximation can be a source of error, particularly in reactions like $\mathrm{H}^{+}+\mathrm{HCN} / \mathrm{HNC} \rightarrow \mathrm{H}+$ $\mathrm{HCN}^{+} / \mathrm{HNC}^{+}$, which are either endothermic or exothermic at low temperature (see below).

In this paper, we present the first measurement of photoionizing transitions of HNC in the vicinity of the $\mathrm{X}^{1} \Sigma^{+} \rightarrow \mathrm{X}^{+2} \Sigma^{+}$ transition, supported by $a b$ initio calculations.

\section{Methods}

\subsection{Experimental details}

The spectrum presented in this paper has been recorded at the DESIRS beamline of the SOLEIL French synchrotron facility 29 with the DELICIOUS III spectrometer. ${ }^{30}$ To generate the HNC molecules, we used a flow-tube reactor inducing $\mathrm{H}$-abstraction from a chosen hydrogenated precursor by reaction with $\mathrm{F}$ atoms. (see Ref. 31] for detailed information). The $\mathrm{F}$ atoms are produced by a microwave discharge applied to a gas mixture of $\mathrm{F}_{2}$ diluted in helium. The precursor, also diluted in helium, is introduced in the flow-tube with an adjustable concentration with respect to that of fluorine atom to yield multiple $\mathrm{H}$-abstractions and thus to generate both HCN and HNC isomers.

In the present study, the precursor was methanimine ( $\mathrm{HN}=\mathrm{CH}_{2}$ ) which leads to both isomers, HCN and HNC depending on which hydrogens are removed. It has been synthesized following an improved version of the procedure described in Ref. 32 . A tube $(30 \mathrm{~cm})$ and two U-traps equipped with stopcocks were fitted on a vacuum line $(0.1 \mathrm{mbar})$. The tube was half-filled with powdered potassium hydroxyde $(50 \mathrm{~g})$ and heated up to $90^{\circ} \mathrm{C}$. The first trap was immersed in a cold bath $\left(-80^{\circ} \mathrm{C}\right)$ and the second one in liquid nitrogen. Aminoacetonitrile $(2.8 \mathrm{~g}, 50 \mathrm{mmol})$ was slowly vaporized on $\mathrm{KOH}$. High boiling point impurities were trapped in the first trap and methanimine in the second one. At the end of the reaction, the stopcocks of the second U-trap were closed and the compound kept in liquid nitrogen (yield: $0.75 \mathrm{~g}$, $52 \%, 26 \mathrm{mmol}$ ).

$\mathrm{HN}=\mathrm{CH}_{2}$ was introduced in the experiment using its vapour pressure at $-78^{\circ} \mathrm{C}$ (dry ice temperature). The flow-tube reactor conditions were optimized to favor two successive H-atom abstractions i.e. the HNC (and $\mathrm{HCN}$ ) production. Even though the two isomers have the same mass, they have different vibronic structures, including a much lower ionization energy for the HNC isomer $(I E(\mathrm{HNC}) \approx 12 \mathrm{eV}$, see Section 3.2), as compared to HCN $\left(I E(\mathrm{HCN})=13.607(2) \mathrm{eV}^{114}\right)$. The ionization energy and corresponding photoelectron energies can thus be used to distinguish the two isomers with the DELICIOUS III spectrometer.

The measurement presented in this paper has been recorded at a fixed photon energy ( $13 \mathrm{eV}$ ) by averaging the signal over 9 hours. The photoelectron spectrum has been obtained from the photoelectron image by using the pBASEX algorithm ${ }^{33}$ to extract the photoelectron kinetic-energy distribution. The ionization energies of water and oxygen, $I E\left(\mathrm{H}_{2} \mathrm{O}\right)=101766.8(12) \mathrm{cm}^{-1}$ $(=12.6175(2) \mathrm{eV})^{34}$ and $I E\left(\mathrm{O}_{2}\right)=97348(2) \mathrm{cm}^{-1}(12.0696 \mathrm{eV})^{35}$, respectively, present in the background gas inside the spectrometer, was used to calibrate the energy scale. The resulting spectrum

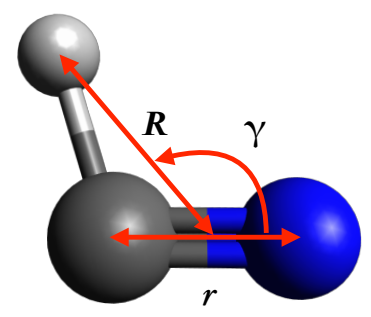

Fig. 1 Representation of Jacobi coordinates $(r, R$, and $\gamma)$. The $\mathrm{H}, \mathrm{C}$, and $\mathrm{N}$ atoms are represented in light grey, dark grey, and blue, respectively.

has a spectral resolution of $60 \mathrm{meV}$ at a binding energy of $12 \mathrm{eV}$ $(1 \mathrm{eV} \text { kinetic energy })^{\frac{36}{6}}$ and the accuracy of the calibrated energy scale is about $5 \mathrm{meV}$.

\subsection{Computational details}

The potential energy surfaces of $\mathrm{HCN}^{+}$in the first three electronic states, two of ${ }^{2} \mathrm{~A}^{\prime}$ and one of ${ }^{2} \mathrm{~A}^{\prime \prime}$ symmetry, have been calculated here. A correlation consistent F12 double zeta atomic basis set ${ }^{37}$, VDZ-F12, was used. Multi-configurational self-consistent field (MCSCF) calculations were performed using 8 and 2 active orbitals of $a^{\prime}$ and $a^{\prime \prime}$ symmetry, respectively, optimizing the average energy of 4 states: the ground state of neutral, and for the cation, two states of ${ }^{2} \mathrm{~A}^{\prime}$ symmetry and one ${ }^{2} \mathrm{~A}^{\prime \prime}$ state. With the resulting molecular orbitals, the ic-MRCI-F12 energies (internally contracted multireference configuration interaction ) of the ${ }^{2} \mathrm{~A}^{\prime}$ and ${ }^{2} \mathrm{~A}^{\prime \prime}$ states of the cation were calculated using the MOLPRO suite of programs. $\frac{38}{3}$

The calculations are done at geometries defined in Jacobi coordinates with $\mathbf{r}$, the $\mathrm{CN}$ internuclear vector, $\mathbf{R}$, the vector joining the $\mathrm{CN}$ center of mass to $\mathrm{H}$, and $\cos \gamma=\mathbf{r} \cdot \mathbf{R} / r R$, where $r$ and $R$ are the modulus of the corresponding Jacobi vectors, see Figure 1 The zero energy is set at the minimum well of the $\mathrm{X}^{1} \Sigma^{+}$ground state of $\mathrm{HCN}$ (at $r_{\mathrm{e}}=1.158 \AA, R_{\mathrm{e}}=1.697 \AA$, and $\gamma=180^{\circ}$ ), and the absolute energies of the $\mathrm{HCN}^{+}$potential energy surfaces were determined from the $a b$ initio calculations described above.

As discussed below, the lowest electronic states of $\mathrm{HCN}^{+}$and $\mathrm{HNC}^{+}$are subject to $\Sigma-\Pi$ vibronic couplings due to conical intersections. In order to properly describe the conical intersections, a diabatic representation is considered, formed by three states with well-defined projection of the electronic orbital angular momentum, $\Lambda=0, \pm 1$. In this $3 \times 3$ subspace, the diabatic states are coupled through the $V_{\mathrm{e}}$ potential term. The Hamiltonian matrix is completely analogous to those used before for treating $\Sigma-\Pi$ vibronic effects,, 39

$$
\mathbf{H}_{\mathrm{e}}=\left(\begin{array}{ccc}
E_{-1}(r, R, \gamma) & V_{1}(r, R, \gamma) & 0 \\
V_{1}(r, R, \gamma) & E_{0}(r, R, \gamma) & V_{1}(r, R, \gamma) \\
0 & V_{1}(r, R, \gamma) & E_{1}(r, R, \gamma)
\end{array}\right),
$$

where $E_{1}=E_{-1}$, and $V_{1}(r, R, \gamma) \propto \sin \gamma$, as $\gamma \rightarrow 0^{\circ}$ or $180^{\circ}$. The adiabatic eigenvalues of this electronic matrix are

$$
E_{1} \quad \text { and } \quad E_{ \pm}=\left(E_{1}+E_{0} \pm \sqrt{\left(E_{1}-E_{0}\right)^{2}+8 V_{1}^{2}}\right) / 2
$$


and can be associated with the $a b$ initio points of the two ${ }^{2} \mathrm{~A}^{\prime}$ and the ${ }^{2} \mathrm{~A}^{\prime \prime}$ surfaces described above. Thus the parameters $E_{0}, E_{1}$, and $V_{1}$ can be directly obtained from the ab initio calculations as previously done for the OHF system 40 .

With the three-dimensional set of $a b$ initio points, the diabatic potential energy surfaces, $E_{0}$ and $E_{1}$, and the coupling, $V_{1}$, of $\mathrm{HCN}^{+}$are interpolated using 3D cubic splines, with the DB3INK/DB3VAL subroutines based on the method of de Boor 41 and distributed by GAMS. 42

The photoelectron spectrum of HNC isomer is calculated using a wave-packet method similarly to that applied to calculate the photodissociation of $\mathrm{HCN} \sqrt{4344}$ and photodetachment of $\mathrm{OHF}^{-} .401$ In the present approach, the transition dipole moment is neglected, and the initial wave-packet is the rovibrational wave function of the neutral HNC isomer. Here we consider three independent transitions, in which the initial wave-packet is placed on one of the 3 diabatic states of the cation. The wave-packet is then propagated within the coupled diabatic representation, using the MADWAVE3 code. ${ }^{45[46}$ The spectra are calculated by doing a Fourier transform of the autocorrelation function. We have propagated the wave-packets for about $10^{5}$ iterations, so that doing the Fourier transform integration within a given time window, the resulting simulated spectra are broadened by a homogeneous width of approximately $0.5 \mathrm{meV}$, much narrower than the experimental resolution (see Section 2.1).

\section{Results and discussion}

\subsection{Topography of the $\mathrm{HCN}^{(+)} / \mathrm{HNC}^{(+)}$isomerization}

The minimum energy path calculated at each angle $\gamma$ (optimizing $r$ and $R$ for each value of $\gamma$ ) is presented in Fig. 2 In Table 1 the optimized values of $r$ and $R$ for $\gamma=180^{\circ}$ and $0^{\circ}$ are reported. The values obtained for the $1^{1} \mathrm{~A}^{\prime}$ surface are in good agreement with experimental works. $47 / 48$

Table 1 Optimized geometries of the $\mathrm{HCN}^{(+)} / \mathrm{HNC}^{(+)}$neutral and cationic isomers (calculated in this work unless specified). All the values are in $\AA$.

\begin{tabular}{cccccc}
\hline & & \multicolumn{2}{c}{$\gamma=180^{\circ}\left(\mathrm{HCN}^{(+)}\right)$} & \multicolumn{2}{c}{$\gamma=0^{\circ}\left(\mathrm{HNC}^{(+)}\right)$} \\
& & $r_{\mathrm{e}}$ & $R_{\mathrm{e}}$ & $r_{\mathrm{e}}$ & $R_{\mathrm{e}}$ \\
\hline neutral & $1^{1} \mathrm{~A}^{\prime}$ & 1.158 & 1.697 & 1.166 & 1.531 \\
& & $1.1533^{a}$ & $1.6861^{a}$ & - & - \\
& & $1.153^{b}$ & $1.686^{b}$ & $1.173^{b}$ & $1.527^{b}$ \\
& & & & & \\
cation & $1^{2} \mathrm{~A}^{\prime}$ & 1.215 & 1.737 & 1.138 & 1.536 \\
& $1^{2} \mathrm{~A}^{\prime \prime}$ & 1.215 & 1.737 & 1.248 & 1.603 \\
& $2^{2} \mathrm{~A}^{\prime}$ & 1.143 & 1.699 & 1.248 & 1.603 \\
\hline
\end{tabular}

${ }^{a}$ Experimental values from Ref. 48 transformed into Jacobi coordinates.

${ }^{b}$ Experimental values from Ref. 47 transformed into Jacobi coordinates

All the states displayed in Fig. 2 exhibit two minima at collinear geometries $\left(\gamma=180^{\circ}\right.$ and $\left.0^{\circ}\right)$, corresponding to the $\mathrm{HCN}^{(+)}$and $\mathrm{HNC}^{(+)}$isomers, respectively.

For $\mathrm{HCN}^{+}$, three states are very close in energy at linear configuration. Two of them are degenerate, forming the ${ }^{2} \Pi$ electronic

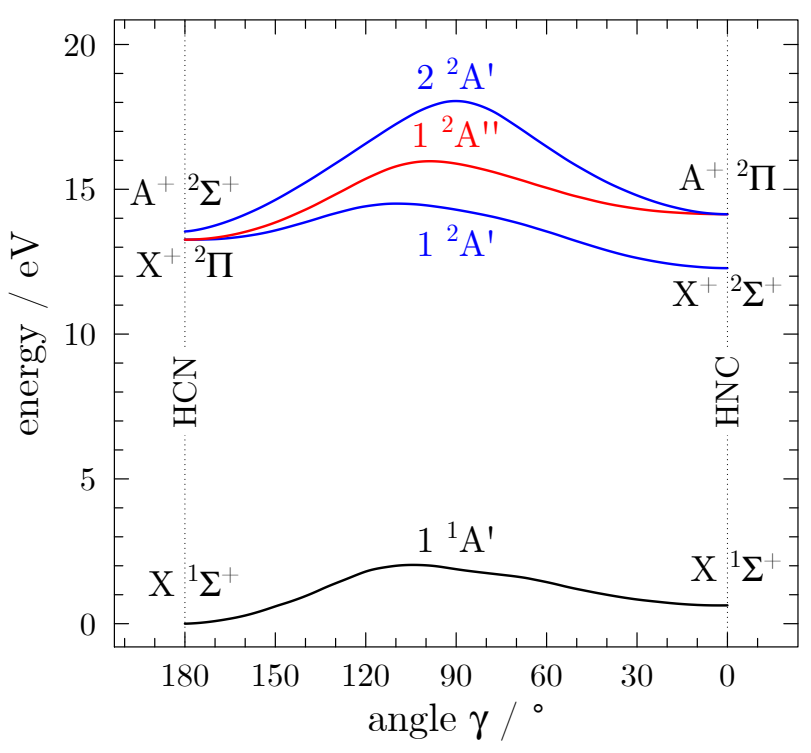

Fig. 2 Minimum energy path for the $\mathrm{HCN} / \mathrm{HNC}$ and $\mathrm{HCN}^{+} / \mathrm{HNC}^{+}$isomerization in the ground state of the neutral and the lowest electronic states of the cation as a function of $\gamma$, with $r$ and $R$ parameters optimized for each value of $\gamma$. (See Figure 1 for geometry conventions.)

ground state of $\mathrm{HCN}^{+}$at $\gamma=180^{\circ}$ and splitting in one ${ }^{2} \mathrm{~A}^{\prime}$ and one ${ }^{2} \mathrm{~A}^{\prime \prime}$ components in the $\mathrm{C}_{\mathrm{s}}$ symmetry group when the system bends. The third state is slightly higher in energy at $\gamma=180^{\circ}$ and corresponds to the first excited state $\left({ }^{2} \Sigma^{+}\right)$of $\mathrm{HCN}^{+}$. Like one of the components of the ground state, the ${ }^{2} \Sigma^{+}$state becomes a ${ }^{2} \mathrm{~A}^{\prime}$ state when $180^{\circ}>\gamma>0^{\circ}$. The lowest ${ }^{2} \mathrm{~A}^{\prime}$ component gives rise to the $\mathrm{X}^{+2} \Sigma^{+}$ground electronic state of $\mathrm{HNC}^{+}$and the upper one, combined with the ${ }^{2} \mathrm{~A}^{\prime \prime}$ component, lead to the ${ }^{2} \Pi$ excited states of $\mathrm{HNC}^{+}$at $\gamma=0^{\circ}$.

Because they have the same symmetry, the two ${ }^{2} \mathrm{~A}^{\prime}$ components stemming from the two lowest electronic states $\left({ }^{2} \Sigma^{+}\right.$and ${ }^{2} \Pi$ states) of $\mathrm{HCN}^{+}$interact and thus repel each other. This situation is typical near a conical intersection between the two ${ }^{2} \mathrm{~A}^{\prime}$ states, giving rise to important $\Sigma-\Pi$ vibronic couplings, as reported for this system by Köppel et al. ${ }^{49}$ The conical intersection is clearly seen in the bottom panel of Fig. 3 at a $r$ distance slightly shorter than the equilibrium distance of the well of the neutral $\mathrm{HCN}\left(r_{\mathrm{e}}=1.158 \AA\right)$. At this linear configuration, the equilibrium $r_{\mathrm{e}}$ distances of the ${ }^{2} \Sigma$ and ${ }^{2} \Pi$ states shift to lower and longer $r_{\mathrm{e}}$ distances, respectively. The large change of the $r$ value upon ionization towards the ${ }^{2} \Pi$ state and the $\Sigma-\Pi$ vibronic couplings lead to the vibrational progression observed in the HCN photoelectron spectrum. 14449,52

The situation for the $\mathrm{HNC}^{+}$isomer, at $\gamma=0^{\circ}$, is rather different. In this case the ${ }^{2} \Sigma\left(=1{ }^{1} \mathrm{~A}^{\prime}\right)$ state shifts to lower energy, resulting in a shift of the conical intersection towards considerably larger $r$ values (top panel of Fig. 3). As a consequence, the $\Sigma$ and $\Pi$ states have a rather different energy and they do not strongly interact at $r_{\mathrm{e}}=1.166 \AA$, in the Frank-Condon region. In addition, the ${ }^{2} \Sigma$ state for the $\mathrm{HNC}^{+}$isomer has an equilibrium distance very close to that of neutral HNC. From that, one can expect to observe a re- 


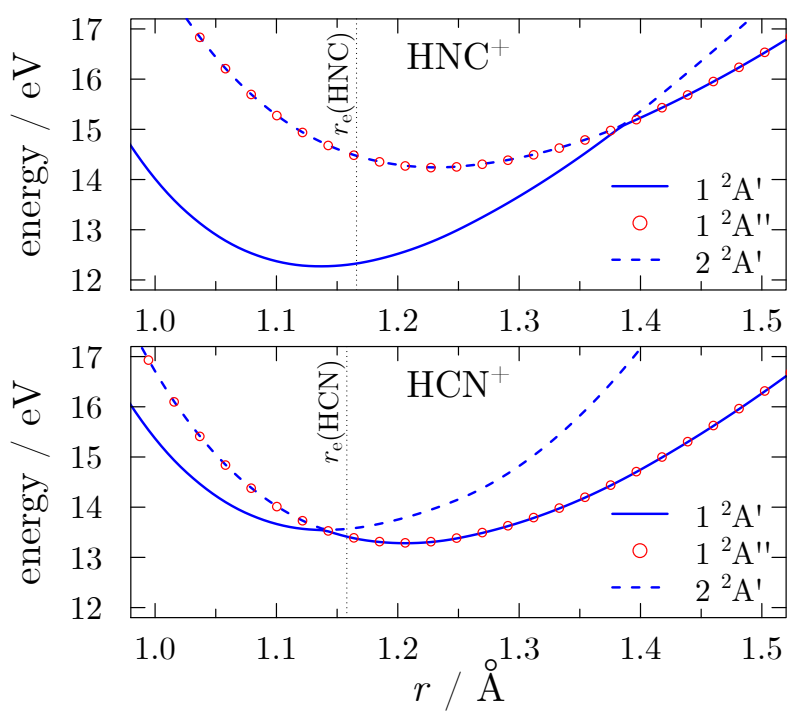

Fig. 3 Potential energy curves of the three lowest electronic states of $\mathrm{HCN}^{+} / \mathrm{HNC}^{+}$system for $R=1.697 \AA$ and $\gamma=180^{\circ}\left(\mathrm{HCN}^{+}\right.$isomer, bottom panel), and for $R=1.531 \AA$ and $\gamma=0^{\circ}\left(\mathrm{HNC}^{+}\right.$isomer, top panel). The degeneracy of the blue lines (full or dashed) and the red circles corresponds to the ${ }^{2} \Pi$ state. The vertical dotted lines indicate the $r_{\mathrm{e}}$ equilibrium distances of the neutral HNC $\left(r_{\mathrm{e}}=1.166 \AA\right)$ and $\mathrm{HCN}\left(r_{\mathrm{e}}=1.158 \AA\right)$ isomers.

duced vibrational progression in the HNC photoelectron spectrum with respect to the one of $\mathrm{HCN}$.

\subsection{Photoelectron spectrum of the HNC isomer}

In Fig. 4. the experimental photoelectron spectrum of the $\mathrm{X}^{1} \Sigma^{+} \rightarrow \mathrm{X}^{+2} \Sigma^{+}$ionizing transition of HNC is depicted (upper panel) and compared with our calculated spectrum (lower panel). To account for the experimental resolution and the rotational structures of the neutral and the cationic states (not considered in our calculation), the calculated spectrum displayed in the lower panel (grey line) has been convoluted with a Gaussian line shape (full width at half maximum $(\mathrm{FWHM})=80 \mathrm{meV}$ ). The resulting spectrum is also presented in the lower panel (black line). Note that the calculated spectrum has been shifted up in energy by $0.371 \mathrm{eV}$ in order to have the origin band of the $\mathrm{X}^{1} \Sigma^{+} \rightarrow \mathrm{X}^{+2} \Sigma^{+}$ transition at the same energy as in the experimental spectrum. The adiabatic ionization energy of HNC is thus the only fitted parameter in our calculated spectrum.

The experimental spectrum consists of one main band located at $12.011 \mathrm{eV}$ corresponding to the origin band of the $\mathrm{X}^{1} \Sigma^{+} \rightarrow$ $\mathrm{X}^{+2} \Sigma^{+}$transition and a weaker band at higher energy $(12.29 \mathrm{eV})$ involving the $v=1$ excited state of the cationic $v_{3}$ vibrational mode (CN stretching mode, see below). The transition towards the ${ }^{2} \Pi$ state of $\mathrm{HNC}^{+}$should appear at approximately the same photon energy as the one of $\mathrm{HCN}^{+}$as expected from the calculations. However, the PES of Fig. 4 has been recorded at $13 \mathrm{eV}$, below the $I E$ of $\mathrm{HCN}(13.6 \mathrm{eV})$ to avoid a saturation of the spectrum by the HCN signal. Thus we cannot provide a measurement of the ionizing transition towards the first excited states of the
$\mathrm{HNC}^{+}$cation.

The different values available in the literature concerning the vibrational wavenumbers of $\mathrm{HNC}^{+}$for the $v_{1}$ (NH stretch), $v_{2}$ (HNC bend), and $v_{3}$ (CN stretch) modes, are compared with our results in Table 2 The overall agreement is satisfactory.

Table 2 Vibrational wavenumbers of the $\mathrm{HNC}^{+}$electronic ground state.

\begin{tabular}{|c|c|c|c|}
\hline Mode & Wavenumber $/ \mathrm{cm}^{-1}$ & Method & $\overline{\text { Ref. }}$ \\
\hline \multirow[t]{4}{*}{$v_{1}$} & 3470 & calc. & this work \\
\hline & 3404 & calc. & 26 \\
\hline & 3464 & calc. & 25 \\
\hline & 3365.0 & exp. ${ }^{a}$ & 53 \\
\hline \multirow[t]{4}{*}{$v_{2}$} & 605 & calc. & this work \\
\hline & 523 & calc. & 26 \\
\hline & 618 & calc. & 25 \\
\hline & 577.7 or $584.5^{b}$ & $\exp ^{a}$ & 53 \\
\hline \multirow[t]{5}{*}{$v_{3}$} & 2260 & calc. & this work \\
\hline & 2163 & calc. & 26 \\
\hline & 2212 & calc. & 25 \\
\hline & 2260 & exp. & this work ${ }^{c}$ \\
\hline & 2195.2 & $\exp ^{a}$ & 53 \\
\hline
\end{tabular}

${ }^{a}$ Measured in neon matrix.

${ }^{b}$ Observed but not assigned to $v_{2}$ by the authors. The NIST recommends $577.7 \mathrm{~cm}^{-1} .54$

${ }^{c} \pm 80 \mathrm{~cm}^{-1}$.

From our calculations, one should expect to observe in the photoelectron spectrum transitions involving all the vibrational modes of the cation $\left(v_{1}, v_{2}\right.$, and $\left.v_{3}\right)$, see lower panel of Fig. 4 The calculated positions of the $2_{0}^{2}, 3_{0}^{1}$, and $1_{0}^{1}$ bands with respect to the origin band are $0.15 \mathrm{eV}\left(1210 \mathrm{~cm}^{-1}\right), 0.28 \mathrm{eV}\left(2260 \mathrm{~cm}^{-1}\right)$, and $0.43 \mathrm{eV}\left(3470 \mathrm{~cm}^{-1}\right)$, respectively, see Table 2. Nevertheless in the present work, the signal-to-noise ratio does not allow an unambiguous assignment of structures corresponding to $v_{1}$ - and $v_{2}$-active transitions. Only the fundamental of the $v_{3}$ vibrational mode can be extracted from our spectrum: $\tilde{v}_{3}=2260(80) \mathrm{cm}^{-1}$ $(=0.28(1) \mathrm{eV})$. This value is in very good agreement with our calculations $(0.28 \mathrm{eV})$, see Table 2

In Table 3, the $I E$ value of HNC obtained in this work is compared with previous experimental works. For completeness, the two most accurate values for HCN are also reported. The only experimental values for HNC found in the literature are the one deduced by Hansel et al. from the $\mathrm{HNC}^{+}+$Xe charge transfer reaction 28 and the recombination energy of $\mathrm{HNC}^{+}$measured by Bieri and Jonsson. 27 Although the uncertainties do not overlap, the agreement is satisfactory.

On the side of the theory, several values have been obtained using different approaches. $[22]$ The value of Koch et al. calculated using the Moller-Plesset perturbation theory $(12.01 \mathrm{eV})$ presents the best agreement with our measurements. 24 


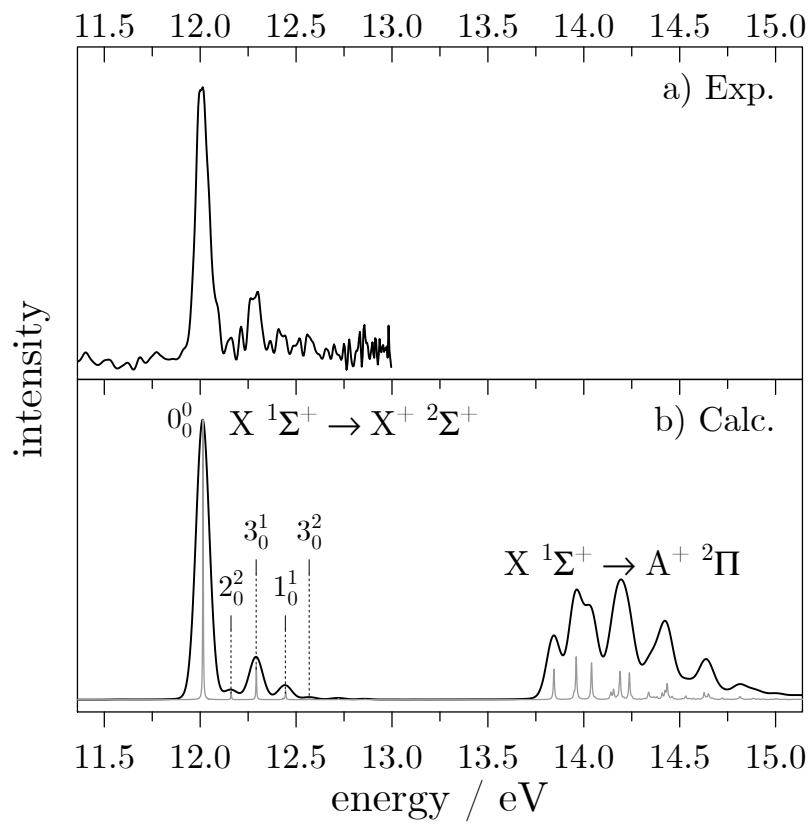

Fig. 4 Photoelectron spectra of HNC: experimental spectrum recorded at $13 \mathrm{eV}$ (upper panel) and calculated spectrum between 11 and $15 \mathrm{eV}$ (lower panel). In the lower panel, the grey line is the calculated spectrum and the black line its convolution with a gaussian line shape $(\mathrm{FWHM}=$ $80 \mathrm{meV})$.

Table 3 Experimental values of the first ionization energy of the hydrogen cyanide isomers.

\begin{tabular}{llc}
\hline & $I E / \mathrm{eV}$ & Ref. \\
\hline HNC & $12.011(10)$ & this work \\
& $12.04(1)^{a}$ & 28 \\
& $12.5(1)^{b}$ & 27 \\
\hline $\mathrm{HCN}$ & $13.607(2)$ & 14 \\
& $13.606(3)$ & 55 \\
\hline
\end{tabular}

${ }^{a}$ Deduced from the $\mathrm{HNC}^{+}+$Xe charge transfer reaction.

${ }^{b}$ Estimation, value of the recombination energy of $\mathrm{HNC}^{+}$.

\subsection{Photoelectron angular distribution of HNC}

The normalized photoelectron angular distribution is described by the well-known parameter, $\beta$, through the expression:

$$
I(\theta)=1+\beta / 2 \times\left(3 \cos ^{2}(\theta)-1\right)
$$

where $\theta$ is the polar angle of ejection with respect to the $\varepsilon$ polarization vector of the light (see Fig. 5). The $\beta$ values have been extracted from the photoelectron image shown in Figure 5 for the transitions to the $v=0$ (origin band) and $v_{3}=1\left(v_{3}=1\right.$ band) levels of cationic ground state, and correspond to 1.14 and 1.2 , respectively. In the absence of theoretical calculations of the photoionization process, which are not within the scope of the present article, we can only compare these values to those found in HCN. In HNC, the highest occupied molecular orbital (HOMO) corresponds to the $5 \sigma$ orbital, and the (HOMO-1) corresponds to the $1 \pi$ orbital, while in $\mathrm{HCN}$, the ordering of these two orbitals is reversed. Holland et al. ${ }^{56}$ have reported the $\beta$ parameters for ionization from these two orbitals close to threshold. For the $1 \pi$ orbital, the origin and $v_{3}=1$ bands gave $\beta$ values around 0.0 and 0.25 , respectively. Unfortunately, the photoelectron bands for ionization from the $5 \sigma$ orbital were overlapped by signal from ionization to higher vibrational levels from the $1 \pi$ band. Nevertheless, the $\beta$ value extracted for these overlapped bands near threshold is $\approx 0.4$, somewhat higher than for ionization from the $1 \pi$ orbital of HCN. This observation is consistent with the present one for HNC, where ionization from the $5 \sigma$ orbital is more anisotropic and gives a relatively large value of $\beta$.

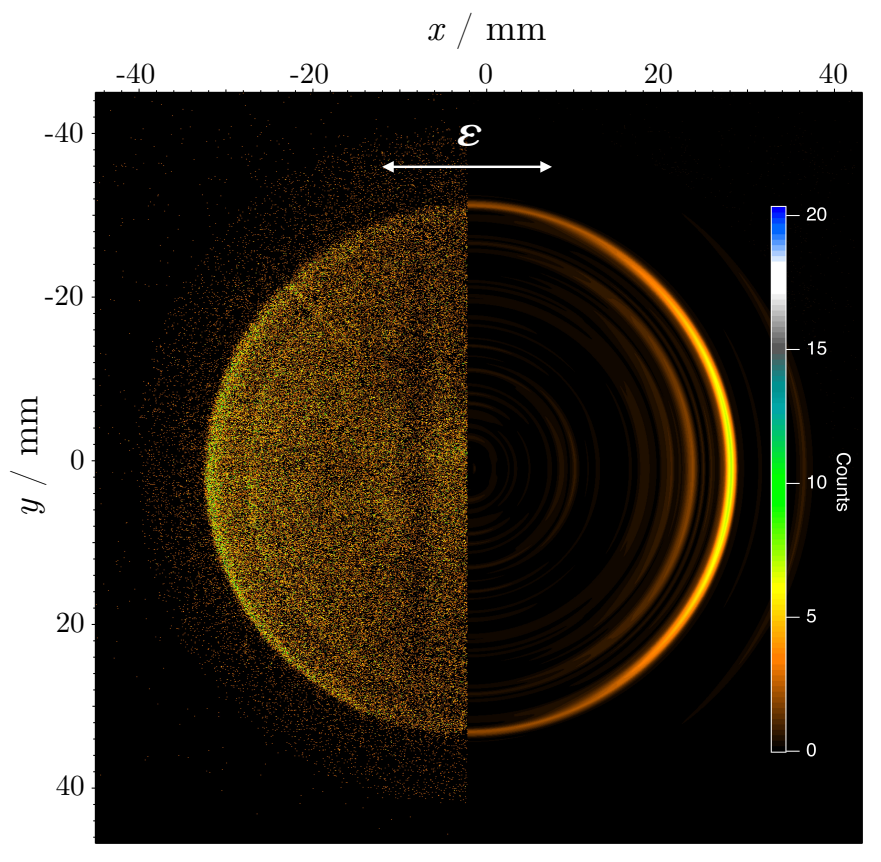

Fig. 5 Photoelectron image of HNC recorded at $13 \mathrm{eV}$ photon energy The left side shows the raw image, while the right side shows the output of the pBasex algorithm. The positive anisotropy discussed in the text is clear for the transitions to both the origin and the $v_{3}=1$ levels of the cation. The white arrow indicates the polarization vector of the synchrotron radiation.

\subsection{Thermodynamics of the HCN/HNC isomers}

The enthalpy of formation of HCN is well known and the preferred value in the literature is $135.1(84) \mathrm{kJ} \mathrm{mol}^{-1} .20121$ Using the precise value of the ionization energy of HCN reported by Fridh and Åsbrink,, 14 one can deduce the enthalpy of formation

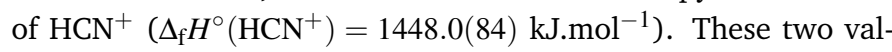
ues are compatible with the ones of the Active Thermochemical Tables, $57[58$ see Table 4.

Although the enthalpy of formation and the $I E$ of HCN are well known, there is relatively little direct experimental data for HNC. Hansel et al. measured the endothermicity of the $\mathrm{HNC}^{+}+\mathrm{CO} \rightarrow \mathrm{HCO}^{+}+\mathrm{CN}$ reaction $\left(31 \mathrm{~kJ} . m o l^{-1}\right) . \stackrel{28}{.2}$ From this value, they derived the enthalpy of formation of $\mathrm{HNC}^{+}$, using literature data. In their paper, the source of the data from the literature was not unambiguously given. Thus, we propose here 
to use other values from the literature combined with their result. Using $\Delta_{\mathrm{f}} H(\mathrm{CO})=-110.5(10) \mathrm{kJ} \cdot \mathrm{mol}^{-1}, 21 \Delta_{\mathrm{f}} H\left(\mathrm{HCO}^{+}\right)=$ $\left.\Delta_{\mathrm{f}} H(\mathrm{HCO})+I E(\mathrm{HCO})=42(1)+786.377(6) \mathrm{kJ} \cdot \mathrm{mol}^{-1}, 59\right] 60$ and $\Delta_{\mathrm{f}} H(\mathrm{CN})\left(434.5(20) \mathrm{kJ} \mathrm{mol}^{-1} 61\right.$ or $439.7(48) \mathrm{kJ}^{-\mathrm{mol}^{-1} 62[63}$ ), we obtain $\Delta_{\mathrm{f}} H\left(\mathrm{HNC}^{+}\right)=1342(3) \mathrm{kJ} \mathrm{mol}^{-1}$ or $1348(3) \mathrm{kJ} \cdot \mathrm{mol}^{-1}$. Note that Hansel et al. obtained $1349(4) \mathrm{kJ} \cdot \mathrm{mol}^{-1}$ close to the latter value.

Using our $I E(\mathrm{HNC})=12.01(1) \mathrm{eV}$ and the two values of $\Delta_{\mathrm{f}} H\left(\mathrm{HNC}^{+}\right)$derived above, we obtain $\Delta_{\mathrm{f}} H(\mathrm{HNC})=$ 184(3) $\mathrm{kJ} \mathrm{mol}^{-1}$ or 189 (3) $\mathrm{kJ} \cdot \mathrm{mol}^{-1}$, respectively. The latter value is in good agreement with the one from the Active Thermochemical Tables with respect to the error bars, $\frac{57}{4}$ see Table 4

In addition, there are two direct measurements of the energy difference between HNC and HCN. First, Maki et al. performed a HCN/HNC equilibrium measurement at high temperature using spectroscopic HNC absorption. 64 Their measurement gave an energy difference ( $\Delta E_{\text {neutral iso. }}$ ) between HNC and HCN of $3600(400) \mathrm{cm}^{-1}=43.1(48) \mathrm{kJ} \mathrm{mol}^{-1}$. Using this value and the enthalpy of formation of HCN, one can deduce the enthalpy of formation of $\mathrm{HNC}\left(\Delta_{\mathrm{f}} H_{0}=178(10) \mathrm{kJ} \cdot \mathrm{mol}^{-1}\right)$. One year later, Pau and Hehre measured the energy difference between HNC and $\operatorname{HCN}\left(\Delta E_{\text {neutral iso. }}=61.9(83){\mathrm{kJ} . \mathrm{mol}^{-1}}^{-1}\right)$ using pulsed ion cyclotron double resonance spectroscopy 65 which leads to an enthalpy of formation of HNC of $197(12) \mathrm{kJ} \mathrm{mol}^{-1}$. It is difficult to explain the differences between the value of Maki et al. and the one of Pau and Hehre, but the results obtained by Pau and Hehre are suported by theoretical calculations $\left(\Delta E_{\text {neutral iso. }}=\right.$ $\left.59.4 \mathrm{~kJ}^{\mathrm{mol}}{ }^{-1}\right) .66$ In addition, one could argue that at high temperature HCN and HNC have a non-negligible reactivity that may affect the HCN/HNC equilibrium; thus, the measurement of Maki et al. may be biased. Using the enthalpies of formation of $\mathrm{HCN}$ and HNC from the the Active Thermochemical Tables, ${ }^{[57}$ we ob-

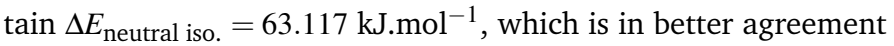
with the value of Pau and Hehre.

From the discussion above, the values proposed by the Active Thermochemical Tables, $\underline{57}$ seem to be very accurate and always confirmed by experimental measurement. Note that from the enthalpy of formation of HNC and $\mathrm{HNC}^{+}$proposed by these tables, one can derive an $I E$ value for HNC of $12.028(14) \mathrm{eV}$, in very good agreement with our present measurement (12.01(1) eV).

\section{Concluding remarks}

Using a flow-tube reactor and a suitable precursor $\left(\mathrm{HN}=\mathrm{CH}_{2}\right)$, the hydrogen isocyanide isomer (HNC) has been efficiently produced in the gas phase, and its photoionization has been studied for the first time at a fixed photon energy $(13 \mathrm{eV})$. The recorded photoelectron spectrum is in good agreement with the photoionizing transition spectrum predicted by wave-packet method based on ic-MRCI $a b$ initio calculation of the potential energy surfaces for the HCN/HNC system. The differences in the photoelectron spectra of the HCN and HNC isomers are explained by the different energy landscapes of their respective Franck-Condon regions. For HCN, a conical intersection between two of the three lowest potential energy surfaces of the cation occurs close to the equilibrium geometry of the HCN ground state, giving rise to important vibronic couplings in the ground state of the cation.
Table 4 Enthalpies of formation of the hydrogen cyanide isomers, their cations, and the $\mathrm{CN}$ radical at $300 \mathrm{~K}$.

\begin{tabular}{|c|c|c|}
\hline & $\Delta_{\mathrm{f}} H^{\circ} / \mathrm{kJ} \cdot \mathrm{mol}^{-1}$ & Ref. \\
\hline \multirow[t]{2}{*}{$\overline{\mathrm{HCN}}$} & $135.1(84)$ & 20 and 21 \\
\hline & $129.283(91)$ & 57 \\
\hline \multirow[t]{2}{*}{$\mathrm{HCN}^{+}$} & $1448.0(84)$ & 20, 21, and 14 \\
\hline & $1442.06(20)$ & 57 \\
\hline \multirow[t]{6}{*}{ HNC } & $178(10)$ & 64, 20, and 21 \\
\hline & 197(12) & 65 \\
\hline & 189(3) & this work and 2862 \\
\hline & 184(3) & this work and 2861 \\
\hline & $188(4)$ & 28 \\
\hline & $192.40(38)$ & 57 \\
\hline \multirow[t]{4}{*}{$\mathrm{HNC}^{+}$} & $1348(3)$ & 2857 \\
\hline & $1342(3)$ & 2861 \\
\hline & 1349(4) & 28 \\
\hline & $1352.9(13)$ & 57 \\
\hline \multirow[t]{3}{*}{$\overline{\mathrm{CN}}$} & $439.7(48)$ & 6263 \\
\hline & $434.5(20)$ & 61 \\
\hline & $440.0(1)$ & 57 \\
\hline
\end{tabular}

This affects the vibrational progressions in the HCN photoelectron spectrum in the vicinity of the first ionization energy. 14$] 49.52$ On the contrary, for HNC no such vibrational progression is expected since the conical intersection is located far from the HNC equilibrium geometry and at higher energy. The experimental spectrum, recorded for the $\mathrm{X}^{1} \Sigma^{+} \rightarrow \mathrm{X}^{+2} \Sigma^{+}$transition, exhibits mainly the $0_{0}^{0}$ origin band and a vibrational band corresponding to excitation of the cationic $\mathrm{CN}$ stretching mode $\left(v_{3}\right)$, for which the fundamental is measured at $\tilde{v}_{3}=2260(80) \mathrm{cm}^{-1}$.

The calculations of the present work predict another photoionization transition, $\mathrm{X}^{1} \Sigma^{+} \rightarrow \mathrm{A}^{+2} \Pi$, involving the first excited electronic state of $\mathrm{HNC}^{+}$and resulting in an extended vibrational progression between 13.7 and $15 \mathrm{eV}$. It would be very interesting to design a gas-phase source enable to produce efficiently the HNC isomer only. This would allow to confirm our prediction and to investigate the vibronic structure of the first excited electronic state of the cation.

The $\beta$ anisotropy parameter for the origin band and the $v_{3}=$ 1 band is extracted from the photoelectron angular distribution of HNC with values around 1.14 and 1.2 larger than what was measured for HCN. This finding is consistent with the different HOMO involved in the photoionization process.

Finally, the measurement of the first adiabatic ionization energy of HNC $(I E(H N C)=12.01(1) \mathrm{eV})$ can be used in combination with the formation enthalpy of $\mathrm{HNC}^{+}$found in the literature to derive the formation enthalpy of neutral HNC: $\Delta_{\mathrm{f}} H(\mathrm{HNC})=$ 184(3) $\mathrm{kJ} \mathrm{mol}^{-1}$ or $189(3) \mathrm{kJ} \mathrm{mol}^{-1}$, depending on which value of the literature is employed for the enthalpy of formation of $\mathrm{CN}$. It appears that the calculated thermodynamic data available in the Active Thermochemical Tables 57 are all in agreement with the experimental values for the $\mathrm{HCN}^{(+)} / \mathrm{HNC}^{(+)}$isomers. Their very 
small error bars make them the preferred values for the thermodynamics of these species.

\section{Acknowledgements}

This work was performed on the DESIRS beamline under Proposal No. 20160376. We acknowledge SOLEIL for provision of synchrotron radiation facilities and the DESIRS beamline team for their assistance. This work received financial support from the French Agence Nationale de la Recherche (ANR) under Grant No. ANR-12-BS08-0020-02 (project SYNCHROKIN) and the CNRS program "Physique et Chimie du Milieu Interstellaire" (PCMI) cofunded by the Centre National d'Etudes Spatiales (CNES). A. A. and O. R. acknowledge support by the Ministerio de Economía e Innovación under grants No. FIS2014-52172-C2 and FIS201783473-C2 and from the European Research Council under the European Union's Seventh Framework Programme (FP/2007-2013) / ERC Grant Agreement n. 610256 (NANOCOSMOS). Work by S.T.P. was supported by the U.S. Department of Energy, Office of Science, Office of Basic Energy Sciences, Division of Chemical Sciences, Geosciences, and Biosciences respectively under contract No. DE-AC02-06CH11357. J.-C.G. thanks the Centre National d'Etudes Spatiales (CNES) for financial support.

\section{Notes and references}

1 G. C. Mellau, A. A. Kyuberis, O. L. Polyansky, N. Zobov and R. W. Field, Scientific Reports, 2016, 6, 33068.

2 H. Liszt and R. Lucas, Astronomy \& Astrophysics, 2001, 370, 576-585.

3 B. E. Turner, L. Pirogov and Y. C. Minh, The Astrophysical Journal, 1997, 483, 235-261.

4 W. Irvine and F. Schloerb, The Astrophysical Journal, 1984, 282, 516-521.

5 P. Pratap, J. E. Dickens, R. L. Snell, M. P. Miralles, E. A. Bergin, W. M. Irvine and F. P. Schloerb, The Astrophysical Journal, 1997, 486, 862-885.

6 T. Hirota, S. Yamamoto, H. Mikami and M. Ohishi, The Astrophysical Journal, 1998, 503, 717-728.

7 J. K. Jørgensen, F. L. Schöier and E. F. van Dishoeck, Astronomy \& Astrophysics, 2004, 416, 603-622.

8 P. Hily-Blant, M. Walmsley, G. Pineau des Forêts and D. Flower, Astronomy \& Astrophysics, 2010, 513, A41.

9 B. Godard, E. Falgarone, M. Gerin, P. Hily-Blant and M. De Luca, Astronomy \& Astrophysics, 2010, 520, A20.

10 J.-C. Loison, V. Wakelam and K. M. Hickson, Monthly Notices of the Royal Astronomical Society, 2014, 443, 398.

11 V. G. Anicich, JPL-Publication-03-19, 2003.

12 D. Talbi, A. L. Padellec and J. B. A. Mitchell, Journal of Physics B: Atomic, Molecular and Optical Physics, 2000, 33, 3631.

13 J. D. Garcia and J. E. Mack, J. Opt. Soc. Am., 1965, 55, 654685.

14 C. Fridh and L. Åsbrink, Journal of Electron Spectroscopy and Related Phenomena, 1975, 7, 119-138.

15 S. Petrie, C. G. Freeman, M. J. McEwan and E. E. Ferguson, Monthly Notices of the Royal Astronomical Society, 1991, 248, 272-275.
16 G. B. Scott, D. A. Fairley, C. G. Freeman, M. J. McEwan, P. Spanel and D. Smith, The Journal of Chemical Physics, 1997, 106, 3982-3987.

17 G. B. I. Scott, D. A. Fairley, C. G. Freeman, M. J. McEwan and V. G. Anicich, The Journal of Physical Chemistry A, 1999, 103, 1073-1077.

18 D. Talbi, Chemical Physics Letters, 1999, 312, 291-298.

19 C. Sheehan, A. L. Padellec, W. N. Lennard, D. Talbi and J. B. A. Mitchell, Journal of Physics B: Atomic, Molecular and Optical Physics, 1999, 32, 3347.

20 M. J. Chase, NIST-JANAF THERMOCHEMICAL TABLES, Monograph 9, Fourth Edition, Journal of Physical and Chemical Reference Data Monographs, 1998.

21 D. L. Baulch, C. T. Bowman, C. J. Cobos, R. A. Cox, T. Just, J. A. Kerr, M. J. Pilling, D. Stocker, J. Troe, W. Tsang, R. W. Walker and J. Warnatz, Journal of Physical and Chemical Reference Data, 2005, 34, year.

22 W. von Niessen, L. S. Cederbaum, W. Domcke and G. H. F. Diercksen, Molecular Physics, 1976, 32, 1057-1061.

23 J. N. Murrell and A. A. Derzi, Journal of the Chemical Society, Faraday Transactions 2: Molecular and Chemical Physics, 1980, 76, 319-323.

24 W. Koch, G. Frenking and H. Schwarz, Naturwissenschaften, 1984, 71, 473-474.

25 K. A. Peterson, R. C. Mayrhofer and R. C. Woods, The Journal of Chemical Physics, 1990, 93, 4946-4953.

26 W. P. Kraemer, P. Jensen, B. O. Roos and P. R. Bunker, Journal of Molecular Spectroscopy, 1992, 153, 240-254.

27 G. Bieri and B.-Ö. Jonsson, Chemical Physics Letters, 1978, 56, 446-449.

28 A. Hansel, C. Scheiring, M. Glantschnig, W. Lindinger and E. E. Ferguson, The Journal of Chemical Physics, 1998, 109, 1748-1750.

29 L. Nahon, N. de Oliveira, G. A. Garcia, J.-F. Gil, B. Pilette, O. Marcouillé, B. Lagarde and F. Polack, Journal of Synchrotron Radiation, 2012, 19, 508-520.

30 G. A. Garcia, B. K. de Miranda, M. Tia, S. Daly and L. Nahon, Review of Scientific Instruments, 2013, 84, 053112.

31 G. A. Garcia, X. Tang, J.-F. Gil, L. Nahon, M. Ward, S. Batut, C. Fittschen, C. A. Taatjes, D. L. Osborn and J.-C. Loison, The Journal of Chemical Physics, 2015, 142, 164201.

32 J.-C. Guillemin and J.-M. Denis, Tetrahedron, 1988, 44, 44314446.

33 G. A. Garcia, L. Nahon and I. Powis, Review of Scientific Instruments, 2004, 75, 4989-4996.

34 F. Merkt, R. Signorell, H. Palm, A. Osterwalder and M. Sommavilla, Molecular Physics, 1998, 95, 1045-1054.

35 R. G. Tonkyn, J. W. Winniczek and M. G. White, Chemical Physics Letters, 1989, 164, 137-142.

36 X. Tang, G. A. Garcia, J.-F. Gil and L. Nahon, Review of Scientific Instruments, 2015, 86, 123108.

37 K. A. Peterson, T. B. Adler and H.-J. Werner, The Journal of Chemical Physics, 2008, 128, 84102.

38 H.-J. Werner, P. J. Knowles, G. Knizia, F. R. Manby, M. Schütz 
and Others, MOLPRO, version 2012.1, a package of ab initio programs, 2012.

39 H. Köppel, W. Domcke and L. S. Cederbaum, in Multimode Molecular Dynamics Beyond the Born-Oppenheimer Approximation, Wiley-Blackwell, 1984, vol. 57, p. 59.

40 S. Gómez-Carrasco, A. Aguado, M. Paniagua and O. Roncero, The Journal of Chemical Physics, 2006, 125, 164321.

41 C. de Boor, A practical guide to splines, Springer-Verlag, Nex York, 1978.

42 R. F. Boisvert, S. E. Howe and D. K. Kahaner, Transactions on Mathematical Software, 1985, 11, 313-355.

43 A. Chenel, O. Roncero, A. Aguado, M. Agúndez and J. Cernicharo, The Journal of Chemical Physics, 2016, 144, 144306.

44 A. Aguado, O. Roncero, A. Zanchet, M. Agúndez and J. Cernicharo, The Astrophysical Journal, 2017, 838, 33.

45 T. González-Lezana, A. Aguado, M. Paniagua and O. Roncero, The Journal of Chemical Physics, 2005, 123, 194309.

46 A. Zanchet, O. Roncero, T. González-Lezana, A. RodríguezLópez, A. Aguado, C. Sanz-Sanz and S. Gómez-Carrasco, The Journal of Physical Chemistry A, 2009, 113, 14488-14501.

47 M. D. Harmony, V. W. Laurie, R. L. Kuczkowski, R. H. Schwendeman, D. A. Ramsay, F. J. Lovas, W. J. Lafferty and A. G. Maki, Journal of Physical and Chemical Reference Data, 1979, 8, 619-722.

48 A. G. Maki, G. Mellau, S. Klee, M. Winnewisser and W. Quapp, Journal of Molecular Spectroscopy, 2000, 202, 67-82.

49 H. Köppel, L. S. Cederbaum, W. Domcke and W. V. Niessen, Chemical Physics, 1979, 37, 303-317.

50 D. W. Turner, Philosophical Transactions of the Royal Society of London A: Mathematical, Physical and Engineering Sciences, 1970, 268, 7-31.

51 J. M. Hollas and T. A. Sutherley, Molecular Physics, 1972, 24, 1123-1131.
52 D. C. Frost, S. T. Lee and C. A. McDowell, Chemical Physics Letters, 1973, 23, 472-475.

53 D. Forney, W. E. Thompson and M. E. Jacox, The Journal of Chemical Physics, 1992, 97, 1664-1674.

54 P. J. Linstrom and W. G. Mallard, NIST Chemistry WebBook ,NIST Standard Reference Database Number 69, National Institute of Standards and Technology, 2010.

55 J. H. D. Eland, T. Field, P. Baltzer and D. M. Hirst, Chemical Physics, 1998, 229, 149-163.

56 D. M. P. Holland, A. C. Parr and J. L. Dehmer, Journal of Physics B: Atomic and Molecular Physics, 1984, 17, 1343.

57 B. Ruscic and D. H. Bross, Active Thermochemical Tables (ATcT) values based on ver. $1.122 d$ of the Thermochemical Network, 2018.

58 T. L. Nguyen, J. H. Baraban, B. Ruscic and J. F. Stanton, The Journal of Physical Chemistry A, 2015, 119, 10929-10934.

59 M. Chuang, M. F. Foltz and C. B. Moore, The Journal of Chemical Physics, 1987, 87, 3855-3864.

60 E. Mayer and E. R. Grant, The Journal of Chemical Physics, 1995, 103, 10513-10519.

61 Y. Huang, S. A. Barts and J. B. Halpern, The Journal of Physical Chemistry, 1992, 96, 425-428.

62 M. Costes, C. Naulin and G. Dorthe, Astronomy \& Astrophysics, 1990, 232, 270-276.

63 J. D. Cox, D. D. Wagman and V. A. Medvedev, CODATA key values for thermodynamics, Hemisphere Pub. Corp., 1984.

64 A. G. Maki and R. L. Sams, The Journal of Chemical Physics, 1981, 75, 4178-4182.

65 C. F. Pau and W. J. Hehre, The Journal of Physical Chemistry, 1982, 86, 321-322.

66 A. E. DePrince III and D. A. Mazziotti, The Journal of Physical Chemistry B, 2008, 112, 16158-16162. 


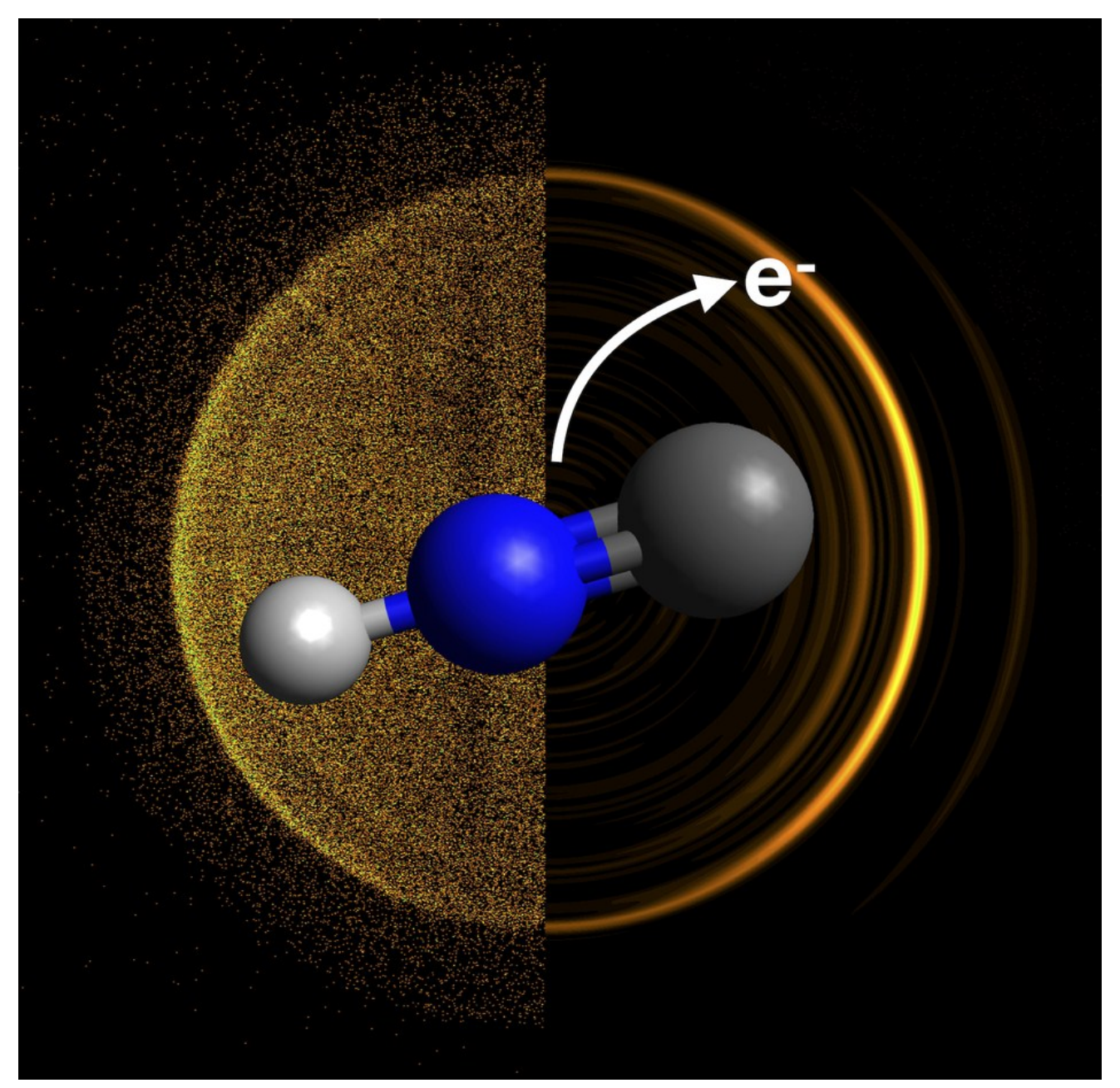

$39 \times 39 \mathrm{~mm}(600 \times 600$ DPI $)$ 